\title{
Adolescents and their aspirations for private car-based transport
}

\author{
Debbie Hopkins $^{1}$ (D) - Enrique García Bengoechea ${ }^{2} \cdot$ Sandra Mandic $^{3}$ (D)
}

Published online: 21 August 2019

(c) The Author(s) 2019

\begin{abstract}
The need to transition away from the current car-dominated transport system is well documented in sustainability, health and transportation literatures. Despite growing interest in active and public transport modes, the car still dominates travel preferences for most age groups. There is, however, some evidence of declining preferences for car-based travel for younger generations. In this paper, we use empirical material gathered through a mixed methods study of high school students in Dunedin, New Zealand, to explore the aspirations of adolescents for private car-based transport. We present and interpret findings from a quantitative survey of high school students $(n=1240)$ and qualitative focus groups $(n=10$ focus groups, 54 participants). Contrary to somewhat optimistic reports of reduced aspiration for driving and cars, we find evidence of ongoing preference for car-based transport, and intentions to learn to drive amongst the cohort of young urban millennials. The findings signal the importance of socialisation processes and everyday travel decisions (e.g. mode choice) for long term aspirations to replicate practices of automobility. Such findings have important implications for interventions to increase non-motorised mobilities, and reduce dependence on private vehicles across the transport system.
\end{abstract}

Keywords High school students · Adolescents · Transport · Mode choice · Motorised transport $\cdot$ New Zealand

Debbie Hopkins

Debbie.hopkins@ouce.ox.ac.uk

Enrique García Bengoechea

enrique.garcia@ul.ie

Sandra Mandic

sandra.mandic@otago.ac.nz

https://www.otago.ac.nz/active-living

1 Transport Studies Unit, School of Geography and the Environment, University of Oxford, Oxford, UK

2 Department of Physical Education and Sport Sciences, Faculty of Education and Health Sciences, University of Limerick, Limerick, Ireland

3 Active Living Laboratory, School of Physical Education, Sport and Exercise Sciences, and the Centre for Sustainability, University of Otago, Dunedin, New Zealand 


\section{Introduction}

A radical and rapid transition away from the current high-carbon transport systemdominated by private car travel-is needed in order to reduce greenhouse gas (GHG) emission at sub-national, nation and global scales, to prevent climate breakdown and to meet the targets set out in the Paris Agreement (e.g. Hopkins and Higham 2016). At the same time, there is growing concern about levels of obesity-and other health concerns-relating, in part, to declining levels of physical activity and increasingly sedentary lifestyles (HSCIC 2016). Rates of driving licencing and car ownership in industrialised countries increased rapidly throughout the 20th century. The "peak car" phenomenon suggested a stabilisation and decline in vehicle kilometres travelled, car ownership and driver's licensing in some countries, and for some generations (Goodwin and Van Dender 2013). As part of this trend, significant behaviour change trends were observed in the adolescents and young adults of the millennial generation. Evidence from several industrialised countries suggested declining preference for car-based travel (Delbosc and Currie 2013). However, these declines; are overwhelmed by demand for private car ownership in some emerging economies and growing cities in the global South (e.g. Yang et al. 2017; Stead and Pojani 2016), have an urban bias, and may be explained by shifts to other (unsustainable) modes (e.g. short haul air travel, Ottelin et al. 2014). Sustained preference for private motorised transport has led some to note the resilience of the dominant mobility regime; 'automobility' (Schwanen 2016).

In this paper, we investigate aspirations for motorised mobility in Dunedin, New Zealand, and examine whether norms and practices which help to replicate automobility (e.g. aspirations for car ownership, intention to learn to drive) are evident in this cohort of teenagers. Thus, this paper contributes to the academic literatures on systemic low carbon transitions through a consideration of the cultural currents underpinning automobility aspirations of adolescents, using quantitative and qualitative data in a mixed methods research design. We begin by bringing strands of research on socialisation, adolescents' mobilities and information communication technologies (ICTs) into conversation, to provide the conceptual framing for this research. We then introduce the survey and focus group methods, before presenting and discussing the findings.

\section{Literature review}

It is broadly agreed that use of active and public transport modes declines as people age. In New Zealand, for example, children and adolescents are more likely to use active and public transport modes than adults (Ministry of Transport 2015). Adolescents who are physically active are more likely to be active adults, with health, financial and environmental benefits across the life course (Trost et al. 2002; Kjonniksen et al. 2008). As a result, a range of interventions have been designed to encourage the active travel of adolescents, and to better understand mobility behaviours in this age group. At the same time, there is evidence to suggest that, in some countries, adolescents ('millennials') are less likely to learn to drive and own a car than other generations (Delbosc and Currie 2013; Chatterjee et al. 2018). The current research sits at the nexus of these issues, examining adolescents' aspirations for motorised mobility, including licence acquisition and car ownership, in the context of rising ICT access and processes of transport mode socialisation. 


\section{Corporeal mobilities, mode choice and socialisation}

There have been numerous reviews of the theoretical constructs that aid understandings of travel behaviour including transport mode choice (e.g. Schwanen and Lucas 2011; Axhausen 2007; Van Acker et al. 2010). With over 70 years of research on the topic, there has been an evolution in the types of approaches, disciplinary perspectives and terminologies adopted, as the study of transport broadened to include insights from the social sciences. Axhausen (2007, p. 2) notes how this body of literature "draws for its concepts on a wide range of disciplines and on its own understandings, which are not necessarily consistent with each other, but often either overlay the same term with multiple, divergent meanings, or provide different terms for the same object or process." Conceptualisations of habits, attitudes, norms and intentions have become central to travel behaviour research.

Transport research based on social psychology draws from generalised models of human behaviour, often using Theory of Planned Behaviour (TPB) (Ajzen 1991), the Norm-Activation Model (NAM) (Schwartz 1977) and the Theory of Interpersonal Behaviour (TIB) (Triandis 1977). TPB has been used in a wide variety of transport research (e.g. Jiang et al. 2017; Hoffmann et al. 2017), and can be used to describe the relationship between behaviour and behavioural intentions and behavioural beliefs, normative beliefs and perceived behavioural control. Following on, behavioural intentions, TPB proposes, can be used to explain actual behaviours. Limitations to the TPB include the exclusion of habitual travel behaviours, the unidirectional linear process which overlooks the role behaviour can have on changing attitudes, and that attitudes may not predict, or conflict with behaviours. These limitations have been addressed, to varying degrees, by modifications to TPB. For instance, Anable (2005) includes measures for habitual behaviour in her paper on driver segmentation. Meta analyses (see, for example: Armitage and Conner 2001) have shown that attitudes, subjective norms and perceived behavioural controls are successful in predicting behavioural intentions, but intentions may be less successful at predicting behaviours. Schwanen and Lucas (2011, p. 18) note that in TPB framings, "individuals are not thought to make decisions in complete isolation from what others think but do so informed by the wider social context and practices of the society in which they live", and this is a useful positioning for the current research.

Cultural determinants of travel behaviours have been discussed from a variety of frames, including Mobility Cultures (e.g. Hopkins and Stephenson 2015), and socialisation. Matthies and Klöckner (2015) use the concept of 'car-fixation' to explain the limited success of interventions to change existing car cultures. They argue that socialisation processes by way of early influences, family, school, media and peer group contribute to an obsession with cars, and that gender and geography both positively correlate with car-fixation: men are more likely than women, and rural residents more than urban, to be fixated on cars. Through processes of socialisation, children and adolescents become aware of, and learn the types of skills, values and patterns of behaviour that assimilate those of the culture within which they live. Through this process, adolescents learn 'good' habits-habits that are temporally and spatially consistent with social norms and values (Maccoby 2015). Travel socialisation theory suggests that children and adolescents will learn about transport modes by way of family, school, media and peer groups, with attitudes of and preference for particular transport modes embedded from childhood (Baslington 2008). This, Baslington (2008, p. 91) argues, means that "car dependency should be viewed as a social problem and tackled from a social policy rather than just a travel demand management approach". 
It has been reported that primary school-aged children already associate status with different modes of transport ([e.g. bicycle, bus, car] Meaton and Kingham 1998). However, there are significant implications of travel-mode socialisation for adolescents, as they enter the life stage where decisions are made about learning to drive. There is significant evidence of the importance of parents in the socialisation of younger children, but for older children and adolescents, peer influence becomes increasingly important. The acquisition of a driver's licence has socio-cultural and economic (e.g. employability) significance which is as important as the technical skills (e.g. Schönhammer 1999; Hopkins 2016). Based on retrospective studies it appears that habit plays an important role in mediating travel mode choice for adolescents and young adults. Moreover, norms relating to modes are influenced by socialisation processes and may play an important role in mode preferences (e.g. Haustein et al. 2009). Flamm and Kaufmann (2006) suggest that socialisation can help to explain the continued dominance of car use, despite discourses of environmental awareness.

\section{Millennials, licence acquisition and virtual mobilities}

There has been significant interest in the travel behaviours of millennials, as a large generation whose travel behaviours will have implications for: the capacity to reduce the environmental impacts of the transport system, health (particularly relating to obesity and cardiovascular disease), infrastructural investment, and funding of future transport systems. Moreover, given the resilience of the system of automobility over the past century, there is curiosity around the factors contributing to potentially different mobility practices of millennials. A series of reviews have been published (e.g. Chatterjee et al. 2018; Delbosc and Currie 2013) that have pointed to the importance of non-transport related factors in shifting millennials travel behaviours-including socio-economic status, delayed adulthood, and the role of social media and online communication. In their synthesis of evidence, Delbosc and Currie (2013, p. 286) state that "there are likely to be multiple interacting factors behind this trend and the combination of factors will vary between countries and even within cities", thus pointing to the highly geographically contingent nature of this phenomenon. Moreover, between different places, the same explanatory factor may affect aspirations for motorised transport differently.

In their qualitative investigation of driver's licence acquisition in the UK, Fylan and Caveney (2018) point to the five motivations; gaining independence, personal space, kudos, expanding social worlds and gaining career opportunities. They noted how non-drivers perceived wider social worlds that were not consistent with how drivers actually used their vehicle and licence, which were often for more mundane types of travel (e.g. commuting). In their research in the US, Thigpen and Handy (2018) found that delays in licensing are associated with attributes and attitudes related to travel, the influence of parents and policies including the graduated driver's licensing scheme. It is still unclear, however, whether adolescents are delaying or forgoing driver's licensing (Le Vine and Polak 2014); in other words, whether young adults today will become drivers at a later life stage. Moreover, Hopkins (2016, p. 149) uses data from Aotearoa New Zealand to show how "justifications for learning to drive goes beyond the competency and capacity to drive independently".

In a study of adolescents' intentions to obtain a driver's licence, and purchase a car in Denmark, Sigurdardottir et al. (2014) find three groups; 'car enthusiasts', 'car pragmatists', and 'car skeptics'. Car enthusiasts have car-oriented social networks and strong instrumental, affective, symbolic, and relational values. Car pragmatists associate instrumental and 
relational values with car ownership but articulate the expense of car ownership as a barrier. Car sceptics reported low interest in a car-mobility future. In a study of Japanese university students, Muromachi (2017) uses a mobility biography approach to enable students to reflect on past experiences of transport-to-school. Previous transport-to-school by bicycle was positively related to intentions of purchasing a car in future (Muromachi 2017).

As the millennial generation is the first to have ubiquitous mobile phone, internet and social media access, there is a great deal of interest into how these innovations may affect social lives, mobilities and health. It has been claimed that information communication technologies (ICT) including social networking are facilitating travel substitution practices that reduce the necessity for corporeal mobility (e.g. Cohen-Blankshtain and Rotem-Mindali 2016), with Rosqvist and Hiselius (2016) suggesting that online shopping could be used to support more sustainable travel behaviours. Yet such propositions are often reliant on individualised understandings of travel behaviour which may overlook broader system dynamics including trip generation, trip chaining practices, and patterns of goods delivery. Delbosc and Currie (2014) identify the potential role of social media for changes to travel behaviours, as did Hopkins (2016), who suggests that social media use may both enable and constrain mobilities for young adults.

In their study of New Zealand millennials, Hopkins and Stephenson (2015) find that the internet, mobile phones and social media are of clear importance to 18-35-year olds. Yet they do not substitute corporeal mobility with virtual mobility for social interactions, but were more likely to do so for internet shopping. Their research also showed how social media is used to facilitate mobilities, aiding the organisation of social events, and shared mobilities across social groups. This finding was replicated by Delbosc and Mokhtarian (2018), who find no evidence to suggest that social media is replacing face to face interaction amongst millennials, and that indeed, social media-based interactions are associated with more frequent face to face meetings. Chatterjee et al. (2018: p. 50) suggest that with long-term trends in ICT use, "activities based around ICTs may displace activities that are reliant on the car, with younger people in the vanguard of this". The authors go on to note the concerning lack of evidence on the 'long term effects of ICT use'.

\section{Case study: Dunedin, New Zealand}

Aotearoa New Zealand (New Zealand hereafter) has a strong culture of car dependence, and one of the highest car ownership rates in the OECD (OECD 2013). New Zealand's transport-related GHG emission intensities are high, the result of low public transport use and a relatively old car fleet leading to a poor average vehicle fuel economy (International Transport Forum 2010; OECD 2015). Transitioning to ultra-low emission vehicles has been touted as a particularly valuable for New Zealand due to its high domestic renewable electricity generation. However, to achieve a meaningful low carbon transition, behaviour change is of critical importance (Hopkins and Higham 2016). In New Zealand, private car travel is the dominant form of transport for work and school travel (Ministry of Transport 2015), and apart from large urban centres, alternative transport modes are rarely used. Moreover, while policy and planning documentation for New Zealand cities frequently call for good quality sustainable transport (public transport, cycling and walking) as a high priority, this rarely evolves into action. This is evidenced by the large number of public transport projects that have been proposed but not pursued over the past 60 years (Imran and Pearce 2015). 
Dunedin is a small city of 120,000 people on the south-east coast of New Zealand's South Island. It is a relatively hilly city, with a growing network of cycleways, and limited public transport. At the time of the research, no mainstream car or lift sharing services operated in Dunedin (with Uber starting service in Dunedin in mid-2018). The 2013 Census provided evidence of Dunedin's high car dependency, and reliance on private cars for commuting (Dunedin City Council 2016). For instance, 14\% of Dunedin city households have access to three or more cars, and 62\% drove to work on the census day (Statistics New Zealand 2013). Relative to other New Zealand cities, Dunedin's population is young and highly educated, with a large university student cohort, but with population growth of just 1.3\% (2006-2013) compared to 5.3\% nationally (Dunedin City Council 2016). Dunedin has a median income of NZ\$23,300, lower than the national median income of NZ\$28,500. The City Council, District Health Board, the University of Otago and Otago Polytechnic are some of the largest employers in the city, accompanied by a growing tech community. Dunedin city has 12 high schools, including single sex and co-ed schools.

This paper investigates adolescents' aspirations for motorised mobility and examines whether norms and practices which help to replicate automobility (e.g. importance attached to driving a car, intention to learn to drive) are evident in this cohort of teenagers. It uses survey and focus group data collected as a part of the Built Environment and Active Transport to School (BEATS) Study conducted in Dunedin, New Zealand in 2014/2015 (Mandic et al. 2016).

\section{Materials and methods}

The research presented here adopted a process of 'convergent parallel' (Cresswell 2013) or 'concurrent triangulation' mixed method research design (Creswell et al. 2003; Pluye et al. 2018). This involves the concurrent but separate collection and analysis of both quantitative and qualitative data. This process allows the researcher to gain greater understanding of the research problem at hand. The empirical data from the quantitative and qualitative strands are used to "more accurately define relationships among variables of interest" (Castro et al. 2010: p. 3). The findings of the quantitative and qualitative method are, therefore, understood as 'evidence' that can be either numeric or verbal text narrative, and are used to examine the same phenomenon, namely aspirations for private car-based transportation. In this approach, each data set is analysed individually using the appropriate protocols, and then the separate results are brought together in thematic interpretation, which is presented in this paper.

Participants All 12 Dunedin secondary schools participated in the BEATS Study in 2014-2015. Schools ranged from decile 5-10. ${ }^{1}$ The decile rating of a school is a "measure of the socio-economic position of a school's student community relative to other schools throughout the country" (Ministry of Education 2016, p. 4). Adolescents (school years 9-13; age 13-18 years) were recruited through their school. Briefly, researchers spoke to invited adolescents at school assemblies or in individual classes. The study was also advertised in school newsletters. All invited adolescents received a study information package for them and their parents. All adolescents signed consent for participating in this study. For adolescents under 16 years of age, parents signed either parental 'opt-in' consent (active consent; parental consent required) or parental 'opt-out' consent (passive consent; parents only signed 'opt-out' consent if they did not wish their son/daughter to participate)

$11=$ most deprived to $10=$ least deprived. 
based on school's preferences. The study was approved by the University of Otago Human Ethics Committee. For more details on the full study protocol, see Mandic et al. (2016).

\section{Quantitative survey methods}

Participants Overall, 1780 adolescents from all twelve Dunedin high schools completed an online survey at their school. After excluding participants with invalid surveys $(n=38)$, incomplete consents $(n=79)$, missing data $(n=291)$ and invalid driving section of the survey (students under driving age claiming to have a driving licence; $n=132$ ), data from 1240 adolescents (69.7\% of the total sample) were included in this analysis.

Survey Adolescents completed an online survey during class time under supervision of researchers. The survey included questions about sociodemographic characteristics, current and intended travel behaviours, driving licence status, motivations for getting the driving licence, attitudes, norms and perceived behavioural control, driving behaviours and driving intentions, travel substitution behaviours, perceived importance of driving and car ownership and material culture (e.g. resources at home) (Table 1). Travel behaviours were assessed using a question "How often do you travel in the following ways (all travel, not just travel to school)?" for different transport modes with response categories "never", "rarely", "sometimes", "most of the time" and "all of the time". Modes used "most/all of the time" were considered dominant transport modes. Preferred travel modes were assessed using a question "What mode of transport would you prefer to usually use (all travel, not just travel to school)?" followed by a question "What is the main reason for your preferred mode of transport stated in the question above?"

Data analysis Initally, data were analysed using descriptive statistics. Continuous data are presented as mean \pm standard deviation. Categorical data are presented as percentage or frequency (percentage). Subsequently, we used ordinal logistic regression to model associations between survey variables and the importance adolescents attach to driving a car. Associations were first examined at the bivariate level. Only variables which were statistically significant at this level were entered in the final multivariate model, where the importance adolescents attach to driving a car was regressed simultaneously on these variables. $p$ value less than 0.05 was considered statistically significant. Clustering of respondents by school was deemed unnecessary based on a non-significant unconditional random intercept model $(p=0.70)$. A non-significant test of parallel lines also indicated that the assumption of parallel slopes (proportional odds) is tenable in the multivariate model ( $p=1.000)$. Data were analysed using SPSS Statistical Package (Version 25).

A few qualifying variables were not used in the multivariate model as they were deemed problematic on particular grounds. This was the case of the importance adolescents attach to owning a car, which was highly correlated with the outcome variable $(r=0.74)$, and internet access at home, whose response options rendered comparison among some groups impractical. Finally, driving licence status was not included in the multivariate model because of overlap in some response categories with intention to get a driving license.

\section{Qualitative focus group methods}

Participants The qualitative material was gathered from ten focus group sessions (one per school; 10 schools) with 54 adolescents (school years 9-13) who participated in the survey 
Table 1 Survey themes and items

\begin{tabular}{|c|c|}
\hline Theme & Items \\
\hline Sociodemographic characteristics & $\begin{array}{l}\text { Age, gender, ethnicity, boarding status, neighbourhood } \\
\text { area deprivation score } \\
\text { Home resources: Number of vehicles, bicycles, desktop } \\
\text { computers and laptop computers } \\
\text { Ownership or access to a mobile phone and portable } \\
\text { technology }\end{array}$ \\
\hline Current and preferred travel behaviours & $\begin{array}{l}\text { Current travel behaviours } \\
\text { Preferred travel modes }\end{array}$ \\
\hline Driving licence status and motivations & $\begin{array}{l}\text { Driving licence status } \\
\text { For adolescents with a driving licence } \\
\text { Age learner's driving licence was obtained } \\
\text { Current driving behaviours } \\
\text { Motivations for getting a driving licence } \\
\text { For adolescents without driving licence } \\
\text { Intention to obtain/not obtain driving licence in future } \\
\text { Motivations to obtain/not obtain driving licence in future } \\
\text { Predicted future driving behaviours }\end{array}$ \\
\hline Driving, behaviours and behavioural intentions & $\begin{array}{l}\text { Social norms: friends' or parents'/guardians' expectations } \\
\text { of adolescents to learn to drive }{ }^{\mathrm{a}} \\
\text { Perceived behavioural control of the learning to drive } \\
\text { process }^{\mathrm{a}} \\
\text { Perceptions of the expectations to drive, the learning to } \\
\text { drive process, driving, environmental concerns, parental } \\
\text { influence and availability of active transport and public } \\
\text { transport options }{ }^{\mathrm{b}} \\
\text { Perceived importance of driving and owning a car, owning } \\
\text { a mobile phone and the latest mobile phone, having a } \\
\text { computer and internet access }\end{array}$ \\
\hline Travel substitution behaviours & $\begin{array}{l}\text { Time spent with friends (after school and in the evenings) } \\
\text { Communication with friends (phone, text or on the } \\
\text { internet) } \\
\text { Seeing friends less in person because of speaking on the } \\
\text { internet or phone }\end{array}$ \\
\hline
\end{tabular}

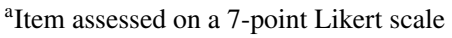

bItem assessed on a 4-point Likert scale anchored in "strongly agree" and "strongly disagree"

Table 2 Sociodemographic characteristics of focus group participants

\begin{tabular}{llll}
\hline School code & $\begin{array}{l}\text { Co-educational sta- } \\
\text { tus of the school }\end{array}$ & $\begin{array}{l}\text { Number of } \\
\text { participants }\end{array}$ & Year levels \\
\hline 1 & Co-ed & 11 & $9,10,11,12$ \\
2 & Girls school & 2 & 9 \\
3 & Boys school & 4 & 9 \\
4 & Co-ed & 3 & $9,11,13$ \\
5 & Co-ed & 4 & $9,10,13$ \\
6 & Boys school & 6 & $9,10,12$ \\
7 & Co-ed & 5 & $9,10,13$ \\
9 & Girls school & 5 & 9,13 \\
10 & Girls school & 9 & 9 \\
12 & Co-ed & 5 & 9,13 \\
\hline
\end{tabular}


(see: Table 2). Efforts were made to include both single sex and co-educational schools and represent all high school years (i.e. years 9-13).

Focus groups The focus groups were run during lunchtime or immediately after school, led by one researcher $(\mathrm{DH})$, and attended by at least one other researcher. The focus groups covered a number of themes including current transport practices, desirability of transport modes, stereotypes of transport users, the built environment, information communication technologies, and socialisation and influences on transport modes previously presented in Mandic et al. (2017). During the focus groups the facilitator encouraged conversation between the participants through which agreements and disagreements could be uncovered and examined.

Qualitative analysis All focus group sessions were digitally audio recorded and fully transcribed. The transcriptions were uploaded to NVivo11 qualitative research software to explore the material and identify themes within and across the ten sessions. The empirical material was thematically coded, a popular approach in qualitative research, with the search for themes equating to the use of variables in quantitative research (Veal 2006). Themes emerged as a result of both inductive and deductive reasoning; drawing together field-generated themes and the overriding conceptual framework (Veal 2006). The analysis identified 12 nodes (19 sub-nodes), which sat within 4 overarching themes as presented in Table 3 below.

\section{Results}

\section{Sociodemographic characteristics}

The research surveyed 1240 adolescents (age: $15.4 \pm 1.4$ years; $46.0 \%$ boys; Table 4 ). At the time of the survey, 788 adolescents were under 16 years of age (under driving age), and 452 were 16 years of age or older (over driving age). In New Zealand, adolescents can begin the learn-to-drive process at 16 years of age. In 2011, the start of the learning-todrive process in New Zealand was raised from 15 to 16 years of age, intended to address New Zealand's death rate for 15-17-year-olds on the road, which was the highest in the OECD (NZTA 2011). Overall, 71.4\% of adolescents lived in households with $\geq 2$ motor vehicles and $56.8 \%$ had $\geq 2$ bicycles available to them. Only $3.7 \%$ did not have motor vehicles at home and $23.6 \%$ did not have access to a bicycle.

In the multivariate ordinal logistic regression, number of vehicles at home was related to perceived importance of driving a car (Table 5). Specifically, adolescents living in homes with one car were more likely to attach importance to driving than adolescents living in homes with no cars and less importance than adolescents living in homes with two or more cars $(p=0.033)$ (Table 5).

\section{Driving licence: current status, intentions and motivations}

In the total sample, $20.8 \%$ of adolescents already had driver's licence and $77.0 \%$ intended to get a driver's licence (Table 4). Ownership of driving licence differed by gender, ethnicity and neighbourhood level deprivation (a measure of the socioeconomic status). Lower proportion of girls, adolescents of Māori and other ethnicities (versus New Zealand European) and adolescents from highest quintile of neighbourhood level deprivation had driving licence (learners or higher) compared to their counterparts (Table 4). However, only 
Table 3 Qualitative analysis, nodes, sub-nodes and frequencies

\begin{tabular}{|c|c|c|}
\hline Theme & Node (number of references) & Sub-nodes (number of references) \\
\hline \multirow[t]{2}{*}{ Transport modes } & Perceptions of modes (4) & $\begin{array}{l}\text { Walking (41) } \\
\text { Bus (34) } \\
\text { Driving a car (31) } \\
\text { Passengering (31) } \\
\text { Cycling (30) }\end{array}$ \\
\hline & Preferred modes (13) & \\
\hline Traffic safety & $\begin{array}{l}\text { Infrastructure: quality and availability (11) } \\
\text { Driver behaviour: perceived safety (10) } \\
\text { Pedestrian behaviour: perceived safety, and } \\
\text { practices (4) }\end{array}$ & \\
\hline \multirow[t]{2}{*}{ Learning to drive } & Incentives to acquire licence (28) & $\begin{array}{l}\text { Independence (15) } \\
\text { Family duties/freedom from family } \\
\text { (7) } \\
\text { Convenience (5) } \\
\text { Better than alternative (e.g. active or } \\
\text { public transport) (4) } \\
\text { Responsibility (CV) (4) } \\
\text { Adult-like behaviour (2) } \\
\text { The 'cool factor' (1) }\end{array}$ \\
\hline & $\begin{array}{l}\text { Disincentives to acquire licence (8) } \\
\text { Role of family, parents and social groups (9) }\end{array}$ & \\
\hline \multirow[t]{2}{*}{$\begin{array}{l}\text { Information } \\
\text { communication } \\
\text { technologies }\end{array}$} & $\begin{array}{l}\text { Activities using Internet (25) } \\
\text { Importance of Internet (14) } \\
\text { Talking with friends (7) }\end{array}$ & \\
\hline & Virtual versus physical meeting (17) & $\begin{array}{l}\text { Value of internet communication (12) } \\
\text { In person or online (7) } \\
\text { Differences in conversation types (6) } \\
\text { Oral versus text (6) } \\
\text { Privacy (6) } \\
\text { Hard conversations (5) } \\
\text { Mixed interpretations (5) }\end{array}$ \\
\hline
\end{tabular}

$2.2 \%$ of surveyed adolescents reported no intention to learn to drive (Table 4). Over half of adolescents aged 16 years and older held at least a learner's licence and most got their driver's licence within 2 years of being legally able to do so. These data are contrary to recent reports of declining licencing amongst the millennial generation in industrialised countries including the UK and Australia (Delbosc and Currie 2013), particularly given the 'urban' environment, with urban youth (broadly conceived) often viewed as the vanguard of changing youth mobility practices. It should be noted here that the participants of this research are younger than those traditionally included in studies of millennials travel behaviour, and this could explain the different preferences, as this cohort could be part of a younger generation.

Half of surveyed adolescents perceived driving a car as very important $(30.1 \%)$ or essential $(21.2 \%)$ and over $40 \%$ perceived owning a car as 'very important' (27.6\%) or essential (14.0\%) (Table 6). A greater proportion of boys, adolescents living in less deprived neighbourhoods and those with restricted or full driving licence reported driving a car and owning a car as 'very important' or 'essential' compared to their counterparts (Table 6). In addition, adolescents living in households with two or more vehicles perceived greater 


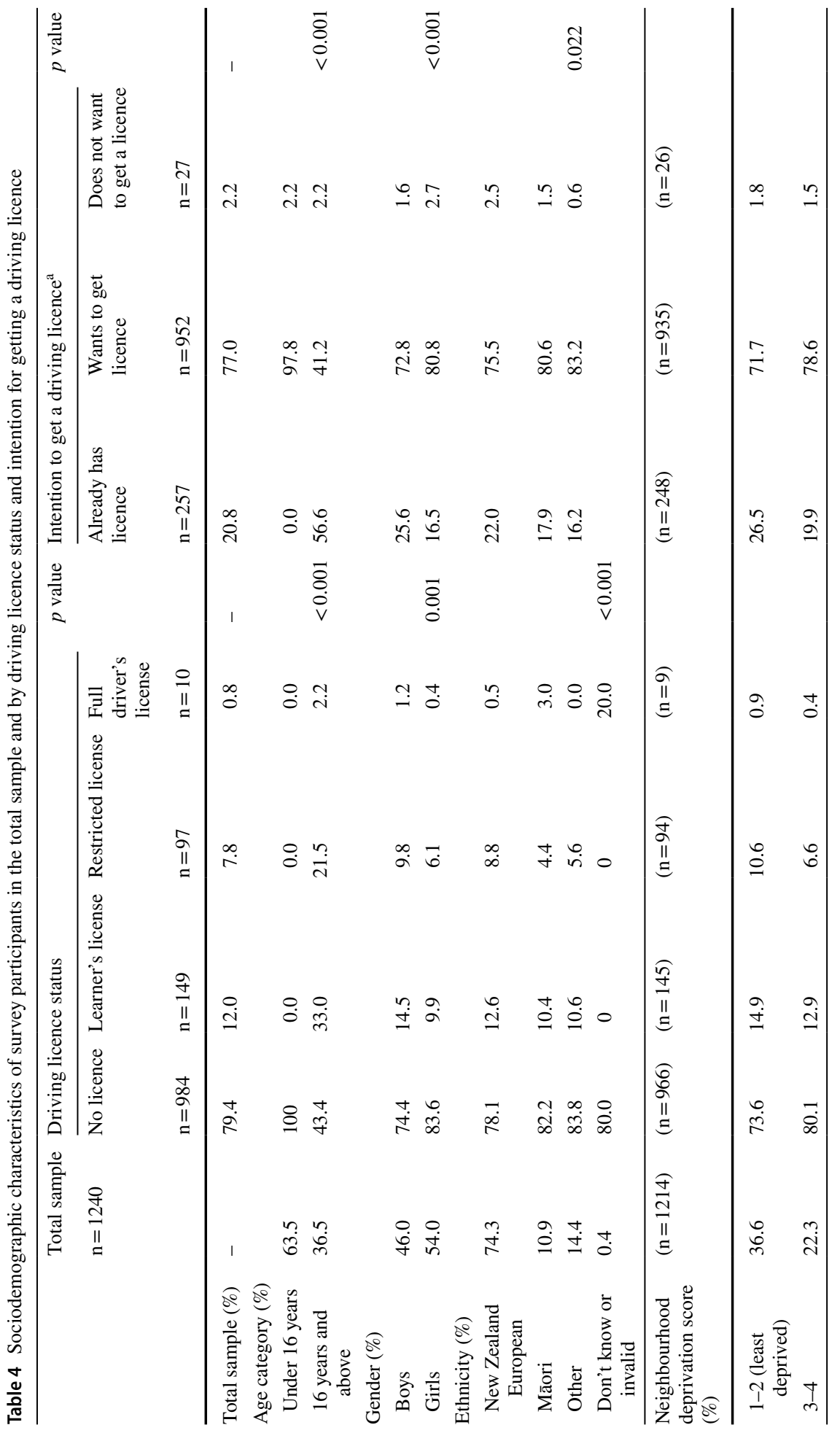




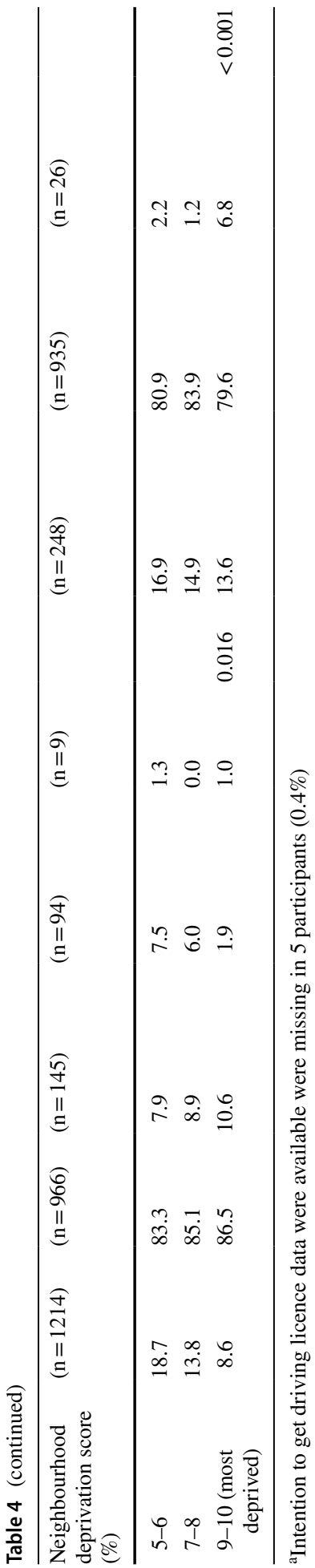


Table 5 Summary of multivariate correlates of importance attached to driving a car

\begin{tabular}{|c|c|c|c|c|c|c|}
\hline & B & SE & Wald & $p$ value & $95 \% \mathrm{CI}$ & \\
\hline \multicolumn{7}{|l|}{ Sociodemographic characteristics } \\
\hline Gender (ref 'female') & 0.20 & 0.13 & 2.41 & 0.121 & -0.05 & .44 \\
\hline \multicolumn{7}{|c|}{ Neighbourhood deprivation score (ref 'most deprived') } \\
\hline Least deprived & 0.42 & 0.24 & 3.04 & 0.081 & -0.05 & .89 \\
\hline Second least deprived & 0.35 & 0.25 & 1.97 & 0.160 & -0.14 & .85 \\
\hline Middle & 0.21 & 0.25 & 0.67 & 0.415 & -0.28 & .70 \\
\hline Second most deprived & 0.40 & 0.26 & 2.42 & 0.120 & -0.11 & .91 \\
\hline Number of vehicles at home & 0.27 & 0.13 & 4.56 & 0.033 & 0.02 & 0.52 \\
\hline \multicolumn{7}{|l|}{ Travel behaviours } \\
\hline Driving a car as main transport mode & 0.49 & 0.16 & 9.46 & 0.002 & 0.18 & 0.80 \\
\hline Driven by others as main transport mode & 0.23 & 0.12 & 4.06 & 0.044 & 0.01 & 0.46 \\
\hline Walking as main transport mode & -0.26 & 0.10 & 7.12 & 0.008 & -0.46 & -0.07 \\
\hline Taxi as main transport mode & 0.03 & 0.12 & 0.06 & 0.805 & -0.21 & 0.27 \\
\hline \multicolumn{7}{|c|}{ Attitudes, norms, and perceived behavioural control } \\
\hline Friends think I should learn to drive & 0.13 & 0.06 & 5.52 & 0.019 & 0.02 & 0.24 \\
\hline Parents/guardians think I should learn to drive & 0.02 & 0.06 & 0.08 & 0.778 & -0.09 & 0.13 \\
\hline Personal control over learning to drive & 0.01 & 0.04 & 0.08 & 0.779 & -0.07 & 0.09 \\
\hline Most people who are similar learn to drive & 0.09 & 0.09 & 1.03 & 0.311 & -0.08 & 0.25 \\
\hline I am nervous about driving/learning to drive & -0.31 & 0.07 & 22.0 & $<0.001$ & -0.44 & -0.18 \\
\hline Need license when I leave secondary school & 0.10 & 0.09 & 1.26 & 0.261 & -0.08 & 0.28 \\
\hline Need driving license to visit friends & 0.29 & 0.07 & 15.3 & $<0.001$ & 0.14 & 0.43 \\
\hline I can go wherever I want to go (freedom) & 0.25 & 0.09 & 8.16 & 0.004 & 0.08 & 0.43 \\
\hline Driving makes people more independent & 0.29 & 0.10 & 9.00 & 0.003 & 0.10 & 0.48 \\
\hline Cars are bad for the environment & -0.15 & 0.07 & 4.01 & 0.045 & -0.29 & -0.01 \\
\hline One or both of my parents drive frequently & -0.06 & 0.10 & 0.38 & 0.539 & -0.25 & 0.12 \\
\hline My parents enjoy driving & 0.27 & 0.09 & 8.09 & 0.004 & 0.08 & 0.45 \\
\hline \multicolumn{7}{|c|}{ Intentions } \\
\hline \multicolumn{7}{|c|}{ Intention to get a driving licence (ref 'does not want to get a license') } \\
\hline Already has license & 1.09 & 0.57 & 3.71 & 0.054 & -0.02 & 2.20 \\
\hline Wants to get license & 1.30 & 0.51 & 6.42 & 0.011 & 0.30 & 2.31 \\
\hline \multicolumn{7}{|c|}{ Socialisation, information and communication technology, and travel substitution } \\
\hline \multicolumn{7}{|c|}{ Owning a portable technology (ref 'no') } \\
\hline Yes & 0.04 & 0.23 & 0.02 & 0.877 & -0.41 & 8.48 \\
\hline Has access but owned by someone else & -0.02 & 0.35 & 0.00 & 0.951 & -0.70 & 0.66 \\
\hline Time spent with friends after school & 0.02 & 0.05 & 0.27 & 0.601 & -0.07 & 0.11 \\
\hline Time spent out with friends in evenings & 0.01 & 0.04 & 0.13 & 0.720 & -0.06 & 0.09 \\
\hline
\end{tabular}

$p$ values $<0.05$ are written in bold to indicated statistical significance

Pseudo $R^{2}$ statistics: Cox and Snell 0.269, Nagelkerke 0.289, McFadden 0.116

importance of car ownership (very important: 29.4\%; essential: $15.4 \%$ ) that those with only 1 car (very important: $23.6 \%$; essential: $11.3 \%$ ) or no cars in a household (very important: 19.6\%; essential: $4.3 \%)(p<0.001)$. Adolescents living in households with two or more vehicles also lived in environments with a greater peer and parental support for learning to 


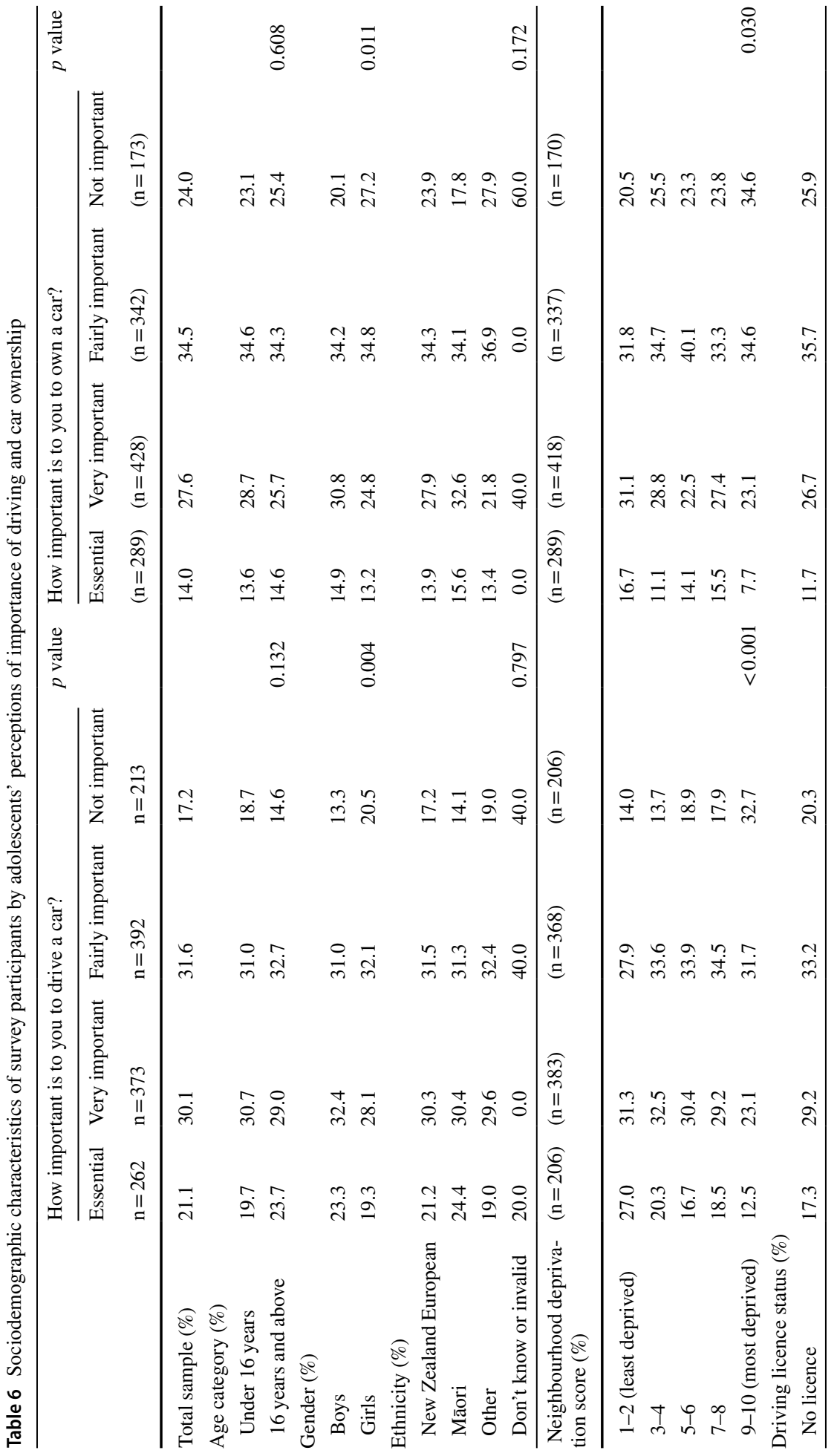




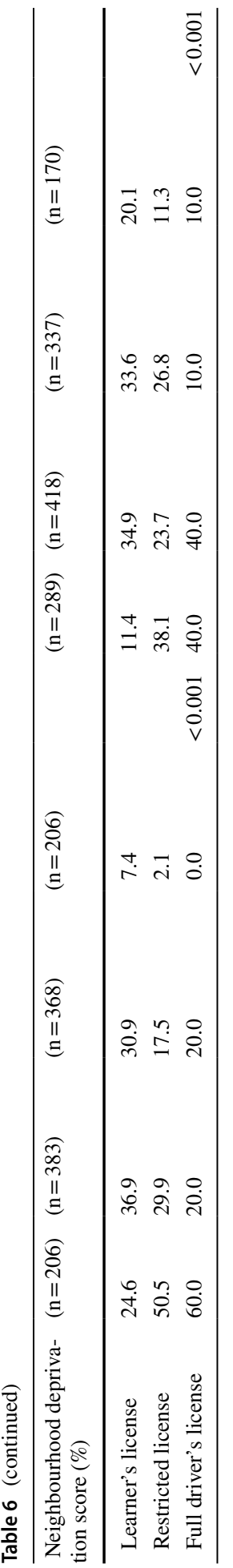


drive, more frequently reported parents driving and enjoying to drive and perceived driving and having driving licence to be more important compared to adolescents living in households with one or no vehicles (data not presented).

The main motivations for getting a driving licence were driving being perceived as convenient (44.4\% of current licence holders; $54.9 \%$ of adolescents intending to get the licence), parental encouragement to learn to drive (24.9\% of current licence holders; $20.8 \%$ adolescents intending to get the licence) and to a lesser extent adolescents' perception that they were expected to learn to drive (11.2\% of current licence holders; $8.8 \%$ adolescents intending to get the licence). Among few adolescents who were not intending to get their driving licence, the main motivations were perceptions that they did not need a driving licence (34.6\%), environmental impact of driving ("driving is bad for the environment", $19.2 \%$ ) and to a lesser extent being too busy to learn to drive (11.5\%).

Intention to get a driving license was related to perceived importance of driving a car in the multivariate ordinal logistic regression model (Table 5). Adolescents wanting to get a driving licence were more likely to attach importance to driving than those not wanting to get a licence $(p=0.011)$.

\section{Travel behaviours}

Overall, most adolescents were driven by others $(68.1 \%)$ or walked $(33.1 \%)$ for transport (Table 7). Among driving age adolescents (16 years and above), $24.6 \%$ reported driving a car as their main mode of transport. Overall, $42.8 \%$ of driving age adolescents with a driving licence reported driving regularly and $56 \%$ of adolescents who intended to get their driving licence in future estimated they would drive regularly. Compared to adolescents under driving age, a smaller proportion of driving age adolescents were driven by others $(61.5 \%$ versus $72.0 \% ; p=0.001)$ and cycled for their general mobility $(1.8 \%$ versus $3.6 \%$; $p<0.001)$ with no significant difference between the groups for other transport modes.

Being driven by others (48.9\%) and driving a car (27.7\%) were the most commonly reported preferred transport modes among surveyed adolescents followed by walking (14.4\%), cycling (3.9\%), public transport - bus (2.9\%) and other modes (2.1\%; skateboarding, scootering or taxi) (Table 6). Among driving age adolescents, driving a car was most commonly reported preferred transport mode (44.6\%) followed by being driven by others (33.3\%). Among adolescents under driving age, being driven by others was most commonly reported preferred transport mode $(58.0 \%)$ followed by driving a car (17.9\%), which could be related due to their inability to gain their learners permit. ${ }^{2}$

Driving a car and being driven by others as main modes of transport emerged as significant correlates of perceived importance of driving a car in the multivariate ordinal logistic regression model (Table 5). Adolescents who drove a car and who were driven by others more often were more likely to attach importance to driving a car than adolescents who use these modes of transport less often ( $p=0.002$ and $p=0.044$, respectively). Conversely, adolescents who walked as main mode of transport were less likely to perceive driving a car as important than those using less frequently this transport mode $(p=0.008)$.

The qualitative focus groups presented a more nuanced picture of preferred mobility, particularly as it related to transport to school. Many students who self-identified as living "too far" from school to use active modes, articulated a desire to use active transport.

2 The learners permit represents the first stage of the graduated driver's licence. 
Table 7 Travel behaviour, preferences, attitudes and norms

\begin{tabular}{|c|c|}
\hline Survey item & $\begin{array}{l}\text { Total sample } \\
\mathrm{n}=1192\end{array}$ \\
\hline \multicolumn{2}{|l|}{ Current modes of travel (used "all of the time" or "most of the time") (\%) } \\
\hline Driven by others & 68.1 \\
\hline Driving a car & 9.1 \\
\hline Walking & 33.1 \\
\hline Cycling & 2.9 \\
\hline Public transport—bus & 15.0 \\
\hline Other $^{\mathrm{a}}$ & 6.6 \\
\hline \multicolumn{2}{|l|}{ Preferred mode of travel (\%) } \\
\hline Driven by others & 48.9 \\
\hline Driving a car & 27.7 \\
\hline Walking & 14.4 \\
\hline Cycling & 3.9 \\
\hline Public transport—bus & 2.9 \\
\hline Other $^{\mathrm{a}}$ & 2.1 \\
\hline Learning to drive $(\%)$ & $(\mathrm{n}=1145)$ \\
\hline My friends think I should learn to drive & 74.8 \\
\hline My parents or guardians think I should learn to drive & 80.8 \\
\hline I have complete personal control over whether or not I learn to drive & 81.1 \\
\hline Most people who are similar to me learn to drive & 79.3 \\
\hline I am nervous about driving/learning to drive & 51.1 \\
\hline Attitudes towards driving $(\%)$ & $(\mathrm{n}=1145)$ \\
\hline I will need a driving license when I leave secondary school & 84.3 \\
\hline I need my driving license to visit my friends & 54.0 \\
\hline When I can drive, I can go wherever I want to go & 80.7 \\
\hline Being able to drive makes people more independent & 85.8 \\
\hline I like being driven around by other people & 67.6 \\
\hline Environmental concerns $(\%)$ & $(\mathrm{n}=1145)$ \\
\hline My transport mode choice can have an impact on the environment & 69.2 \\
\hline Cars are bad for the environment & 74.4 \\
\hline Parental influence (\%) & $(\mathrm{n}=1145)$ \\
\hline One or both of my parents/guardians drive frequently & 90.0 \\
\hline My parents/guardians enjoy driving & 80.9 \\
\hline Availability of other transport options (\%) & $(\mathrm{n}=1145)$ \\
\hline I am able to use public transport to get where I need to go & 64.5 \\
\hline I am able to use active transport (such as walking or cycling) to get where I need to go. & 65.9 \\
\hline
\end{tabular}

${ }^{\mathrm{a}}$ Other modes of transport combined data for skateboarding, scootering and taxi

Adolescents also discussed positive attributes of active transport modes, which include being outside/fresh air, financial cost, environmental awareness, and enjoyment.

Interviewer: Why do you think that [walking \& cycling are] the ideal?

Participant B: Because you get to feel the warm air, and it's fun walking or biking.

Participant C: I just like biking. You feel good afterwards; it's nice to be out. 
Participant D: Walking [is best] because it will cost less money and it would save the environment.

[Focus Group \#06]

The social dimensions of different transport modes were also uncovered through the focus group discussions, with the opportunities for socialising when using public transport modes in particular noted, which may suggest that there are diverse factors contributing to modal choice, which need to be better understood in policy interventions to decrease cardependence, or increase the uptake of active and/or public transport modes.

I would probably still catch the bus because I like being with people and travelling to school together and then you talk to your mates about what's happening. It's just easier than getting in the car with your mum and dad. [Participant D, Focus Group \#07]

Thus, the focus groups present an alternative vision of preferred transport modes and illuminate some interest in adopting alternative transport modes. Moreover, they highlight the family dynamics, and socialisation processes that inform transport decision making, particularly for transport to school. Other factors that impact upon transport decision making and contribute to sustained use of motorised transport modes included weather, topography, and perceived safety of the built environment, as suggested previously by Mandic et al. (2017).

\section{Attitudes, norms, and perceived behavioural control}

The survey results provide evidence of strong social norms prioritising motorised mobility, and in particular, learning to drive. Most adolescents reported that their parents/guardians and friends thought they should learn to drive (Table 7). There was also relatively strong evidence of perceived parental role-modelling, with most adolescents stating that their parents drove frequently and enjoyed driving. Most adolescents perceived strong behavioural control, and only half felt anxious about learning to drive. Most adolescents also perceived a need for a driving licence after leaving high school and perceived that driving 'makes people more independent'. Two thirds of the adolescents perceived that public transport and active transport were suitable for their mobility needs.

In the multivariate ordinal logistic regression model, perceptions that friends expect adolescents to learn to drive and considering driving bad for the environment were related to perceived importance of driving (Table 5). Specifically, adolescents who perceived more strongly that their friends thought they should learn to drive attach more importance to driving a car than those who perceived less expectation $(p=0.019)$, while adolescents thinking more strongly that cars were bad for the environment were less likely to attach importance to driving than those with more mitigated perceptions about the environmental impact of cars $(p=0.045)$.

In the multivariate ordinal logistic regression, adolescents were also more likely to attach importance to driving a car if they perceived that a license is necessary to visit friends $(p<0.001)$, considered that driving a car affords freedom $(p=0.004)$ and independence $(p=0.003)$, and perceived that parents enjoyed driving $(p=0.004)$ (Table 5). On the other hand, adolescents attached less importance to driving a car when they reported being nervous about driving $(p<0.001)$ (Table 5).

The qualitative focus groups identified a range of motivations to learn to drive. While most participants intended to learn to drive before leaving school, others articulated a desire to wait until the completion of tertiary education. The qualitative material uncovers 
a detailed understanding of behavioural intentions. Seven themes arose as motivation for learning to drive: (1) Driving is better than relying on active or public transport, (2) Convenience of motorised mobility, (3) The 'cool factor', (4) Family dynamics including encouragement, helping with chores, (5) Independence, (6) A skills to report on their CV, and (7) Because it is 'adult like' behaviour. The highly mobile and spatially diverse nature of school activities appear to underpin many of the adolescents' mobilities. Some of these themes are evidenced below:

Interviewer: So why do you think you'll get [your driver's licence] straight away?

Participant D: Because then you don't have to rely on transport from your parents or the bus timetable you can just go out whenever you want.

Participant C: If you want to go out with your friends you don't have to say, "Well can you drive me?" You can just drive yourself.

Participant E: It would be more convenient for them as well as us.

Interviewer: For your parents?

Participant E: Yeah, you can just be like, "I'm going here". They don't have to like run around after you.

Participant B: Take yourself to your own sports games and stuff like that.

Participant K: It can make you more helpful too.

[Focus Group \#03]

Independence emerged as a particularly important theme, with adolescents discussing the constraints of reliance on family members and public transport timetables. The importance of developing independence in adolescence is well-documented, and this is coupled with the perceived convenience of having a driver's licence particularly for more rurally-located adolescents, for whom alternative modes (active and public transport modes) were unavailable, and thus dependence on parents, siblings and friends is magnified.

\section{Socialisation, ICTs and travel substitution}

Overall, $57.5 \%$ of adolescents owned a mobile phone and $86.7 \%$ owned a portable technology (such as smart phone, tablet and/or iPad) with mobile internet access (Table 8). On average adolescents had one desktop computer $(0.9 \pm 0.9)$ and two laptop computers at home $(2.0 \pm 1.2)$ and over half had unlimited access to internet at home (55.6\%). Majority of adolescents perceived it as 'important' or 'essential" to have the internet access (77.5\%), own a mobile phone $(70.8 \%)$ and own a computer (58.5\%). On average adolescents spent $4 \mathrm{~h} /$ day on the internet, spent time with friends after school and in the evenings on 2 days/ week and $48.4 \%$ communicated with their friends on the phone or computer every day (Table 8). Overall, one third of adolescents agreed that they see their friends in person less due to communication on the internet or telephone. No variables in this category emerged as statistically significant in the multivariate ordinal logistic regression model.

Themes on travel substitution were also examined through the qualitative focus group sessions, with participants referring to online conversations as 'less exciting' and identified a lack of privacy and misinterpretation of online conversations as factors which differentiate online and face-to-face communications.

Participant D: ...Conversations on the internet [are] often a little less exciting because generally speaking when you're having conversations face to face you get more said in the time. Kind of your brain's going ahead often it could be 'oh hang on' that's like if we're way in advance of where the actual conversation is at. As 
Table 8 Information communication technologies and travel substitution behaviours

\begin{tabular}{ll}
\hline Survey item & Total sample \\
\hline & $\mathrm{n}=1126$ \\
Access to information communication technologies & 57.5 \\
Owning a mobile phone $(\%)$ & 86.7 \\
Owning a portable technology (with internet access) (\%) & 55.6 \\
Unlimited internet access at home (\%) & $(\mathrm{n}=1105)$ \\
Travel substitution behaviours & $4.3 \pm 2.6$ \\
Time spent on the internet (on phone or on a computer) (hours/day) & $2.2 \pm 1.6$ \\
Time spent with friends after school (out of 5 days) (n) & $1.9 \pm 1.9$ \\
Time spent out with friends in evenings (out of 7 days) (n) & 2.2 \\
Time spent talking with friends on phone or internet (\%) & 8.6 \\
Never & 8.5 \\
Rarely & 14.6 \\
1 or 2 days/week & 17.7 \\
3 or 4 days/week & 48.4 \\
5 or 6 days/week & 28.4 \\
Every day & \\
\hline see my friends less in person because we speak on the internet or phone (\% agree) & \\
\hline
\end{tabular}

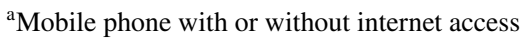

opposed to in face to face where you can get though a lot more, a lot quicker.

Participant F: People take things the wrong way sometimes, like someone's trying to say something but people take it in a different way. It's not very private as well, like on Facebook as well unless you block, everyone can go on it.

[Focus Group \#02]

Participants spoke of the very different types of conversation, and often more simple discussions that occur online, and which are then complemented with more complex and indepth conversations face to face. This reinforces the need for physical travel in order to engage in social interactions.

Interviewer: What sort of conversations do you have over the internet? Are they the same [as face to face]?

Participant B: They're not the same. "What you doing?", "Not much", "You?", "Not much". That's the conversation.

Participant F: Silly little things.

Participant C: Sometimes it's nice to talk to people over Facebook instead of face to face, if it's something you don't want to [talk] face to face about. Like maybe like a rumour or something.

Participant F: I think the term 'what are you doing?' is a lot more common on Facebook like than when you see someone because like if I went up to someone and said it...

Participant B: Well if you're with someone you can see what they're doing!

[Focus Group \#03] 
These findings suggest that ICT and social-media communications are unlikely to be reducing the need for corporeal mobilities amongst millennials, as they are used in different ways, offering an alternative type of communication, but not replacing corporeal mobility and the desire to meet in person. Thus, the focus group material suggests that a substitution effect is unlikely and may not have an impact on preferences for motorised mobility and independent (motorised) travel.

\section{Discussion and implications}

From the quantitative and qualitative material gathered with millennials in Dunedin, New Zealand, we find evidence of continued aspirations for car-based transport among this cohort. Our quantitative data indicate a preference for private car travel above all other modes of transport and a desire for and intention to learn to drive. Consistent with the role of intentions in the transport behaviour literature (Jiang et al. 2017; Hoffmann et al. 2017), intention to drive a car was the factor showing the strongest association with the importance millennials attach to diving a car in the multivariate regression analysis. Driving a car, however, was not perceived to be essential, but of medium importance. This could suggest that while learning to drive is an aspiration for young people, it may also be a normalised expectation in the transition from childhood to adulthood, as previously reported (Hopkins 2016), and socialised in such a way that it is consistent with existing socio-cultural norms. Owning a mobile phone and having internet access were, on the other hand, perceived to be of more crucial importance. Yet this was not reflected in travel substitution behaviours, thus methods and modes of communication are diversifying, but automobility endures.

From our analyses we see that socialisation is indeed an important factor, which contributes positively to adolescents attaching importance to driving a car (Haustein et al. 2009; Klöckner and Matthies 2012). For instance, driving and being driven as the 'usual' mode of transport (for general travel), high numbers of vehicles at home, and peer-expectations of learning to drive are all associated with positive perceptions of car-based travel. Conversely, walking as current dominant transport mode, nervousness about learning to drive and perceptions that cars are bad for the environment all contribute negatively to perceptions about importance of driving. As travel patterns from adolescence may continue into adulthood (Falconer et al. 2015) the importance of the adolescence period for the establishment of lifelong travel patterns, practices and norms is clear. From these findings, it is evident that an adolescent's current travel mode may have an important relationship with their future transport aspirations. In other words, adolescents may be socialised into carcentric mobility futures through practices, discourse, norms and values, which they may then reproduce (and share) through the life course. Changing everyday practices is thereby important to achieve long-term, systemic transitions away from high-carbon and unsustainable modes (e.g. private car travel).

The provision of public transport and active transport infrastructure in Dunedin, and home location are features over which adolescents are not likely to have agency, yet these factors are important for modal choice, and may perpetuate the dominance of automobility if, for instance, public transport is not available, or perceived to be unsafe, impractical or expensive, or affordable housing is not serviced by active and public transport networks. In particular, urban planning practice that prioritises sprawled development increases the need 
for motorised transport and decreases uptake of active modes (Ewing and Carvero 2010). This approach has dominated New Zealand's cities, with deeply embedded cultural aspirations for a 'quarter-acre paradise' (Preval et al. 2010), with such discourses and material realities contributing to vehicle ownership and use.

Our findings reflect high car ownership (OECD 2013, 2015), and shows the importance of internet and mobile phones for adolescents. However, contrary to some assumptions on travel substitution, the quantitative and qualitative material show the importance of corporeal mobility and face-to-face communication. Thus, practices and norms that promote independence and flexibility, perpetuate, and support the continuation of private car-based transport. Norms and aspirations relating to learning to drive exposed through this research align in many ways with the more nuanced findings previously reported in young adults in New Zealand (Hopkins 2016, 2017). Travel substitution through the use of mobile technologies (Lyons 2009) has been suggested as a feature of adolescents' mobility practices that are unique for the millennial generation due to arguably ubiquitous use of social media sites (Gössling 2016). Nevertheless, our research suggests that a substitution effect may be less pronounced than often reported; further research is needed to assess the generalisability of this finding.

The findings point to strong subjective norms prioritising private car-based transport and learning to drive as a mobility-based competency for adolescents. The survey participants reported family members as important motivators for learning to drive behaviours and attitudes. Previous research has shown that parents are 'critical gatekeepers' in the mobility decisions for children and adolescents (Kerr et al. 2006; Lorenc et al. 2008), particularly relating to active transport to school decisions (Hopkins and Mandic 2017; Huertas Delgado et al. 2017; Aibar et al. 2018), and learn to drive behaviours (Hopkins 2016). As such, mobility practices of adolescents need to be understood in the context of family pressures, relationships and interactions. Only by understanding the individual mobilities of adolescents nested in the context of their caregivers, siblings, friends and social networks can strategies and interventions to reduce car-fixation and car-dependence be designed. Thus, understanding the relational mobilities of adolescents and their specific geographic and social contexts is crucial.

Just $2.2 \%$ of adolescents reported no intention to learn to drive. A lack of perceived need for a driving licence was the dominant reason for this stated intention, followed by environmental concerns. The survey found relatively strong evidence of adolescents' awareness of the environmental impacts of motorised transport, with nearly three quarters of the total sample agreeing that 'cars are bad for the environment', and such perceptions contributed negatively to attaching importance to driving a vehicle in the multivariate model. There was also a strong perception of personal behavioural impact on the environment, with nearly $70 \%$ of the whole sample agreeing that their mode choice could impact upon the environment, although this perception did not reach statistical significance in the multivariate model. Thus, in addition, to considering the relational contexts of adolescents' mobilities, using appropriate environmental education strategies may be another promising way to address car-fixation and car-dependence. However, the dominant preference for motorised transport indicates that these perceptions are weaker than motivations to engage in automobility.

If, as this research shows, adolescents have continued aspirations for private car-based transport, greater efforts must be made to improve the availability and quality of alternative transport modes (i.e. active transport and public transport), as well as actions to challenge pervasive socialisation processes and current (unsustainable) travel behaviour patterns. The research presented in this paper suggests that, as previously argued by Schwanen (2016), 
automobility may be resilient to external pressures, insomuch as the system adapts to changing socio-economic and socio-cultural contexts. The deeply embedded nature of automobility reinforces the hegemony of motorised transport, and particularly the private car, and the growth of associated externalities including environmental degradation, and negative impacts on health and well-being.

Although the survey sample included a representative sample of adolescents from in one New Zealand city, our findings may not be generalisable to other geographical settings including rural areas and more deprived areas of New Zealand with higher proportion of Māori and Pacific adolescents or internationally. Given that only $2.2 \%$ of the total sample (27 adolescents) reported no intention to get a driving license, this variable, despite its relevance to the literature, was not deemed appropriate for use as outcome variables in a multivariate model. However, the findings do point to some trends in mobility practices, norms and material culture that may be identified in other geographic contexts. Future studies could replicate this research in other geographical settings to identify similarities and differences in adolescents' aspirations for private car-based transport.

\section{Conclusions}

The findings presented in this paper suggest that in some places, driving and private vehicle ownership as manifestations of automobility may have the 'capacity to endure' (Schwanen 2016). The research exposes the desire to learn to drive and aspirations for car-based transport for adolescents. While owning, and driving a car were not perceived to be essential, traditional mobility norms and practices that prioritise motorised transport are evident, with socialisation of mobility norms and current travel mode patterns arising as important factors regarding the importance adolescents attach to driving. Our findings suggest that ICT and social-media communications are unlikely to be reducing the need for corporeal mobilities, and thus may not have an impact on adolescents' preferences for motorised mobility. Thus, as suggested in previous research, norms and aspirations for motorised transport are being replicated by many young people. In order to transition away from high-carbon transport modes, more concerted attention needs to be paid to the everyday mobility practices of children and adolescents, as well as the underlying norms, values, aspirations, and socialisation processes (including family dynamics) that are locking-in and replicating unsustainable transport behaviours and mobility practices, which may continue across the life course.

Acknowledgments The BEATS Study is a collaboration between the Dunedin Secondary Schools' Partnership, Dunedin City Council and University of Otago. The authors would like to acknowledge the BEATS Research Team members, BEATS Advisory Board, research personnel and the contributions of the school boards, teachers, school principals, and student participants. The BEATS Study was supported by the Health Research Council of New Zealand Emerging Researcher First Grant (14/565), National Heart Foundation of New Zealand (1602 and 1615), Lottery Health Research Grant (Applic 341129), University of Otago Research Grant (UORG 2014), Dunedin City Council and internal grants from the School of Physical Education, Sport and Exercise Sciences, University of Otago. DH was funded through the Ministry of Business Innovation and Employment grant number: CONT-42734-EMTR-UOO.

Authors' contributions DH: Data collection, qualitative fieldwork design, qualitative analysis, literature search and review, led paper writing. EGB: Statistical data analysis, interpretation of empirical material, paper writing. SM: Overall project conceptualisation, data collection, statistical analysis and interpretation, paper writing. 
Open Access This article is distributed under the terms of the Creative Commons Attribution 4.0 International License (http://creativecommons.org/licenses/by/4.0/), which permits unrestricted use, distribution, and reproduction in any medium, provided you give appropriate credit to the original author(s) and the source, provide a link to the Creative Commons license, and indicate if changes were made.

\section{References}

Ajzen, I.: The theory of planned behaviour. Organ. Behav. Hum. Decis. Process. 50, 179-211 (1991)

Aibar, A., Mandic, S., Generelo Lanaspa, E., Gallardo, L.O., Zaragoza, J.: Parental barriers to active commuting to school in children: does parental gender matter? J. Transp. Health 9, 141-149 (2018). https:// doi.org/10.1016/j.jth.2018.03.005

Anable, J.: 'Complacent Car Addicts' or 'Aspiring Environmentalists'? Identifying travel behaviour segments using attitude theory. Transp. Policy 12(1), 65-78 (2005)

Armitage, C.J., Conner, M.: Efficacy of the theory of planned behaviour: a meta-analytic review. Br. J. Soc. Psychol. 40(4), 471-499 (2001)

Axhausen, K.W.: Concepts of travel behavior research (2007). https://www.researchgate.net/publicatio n/237262766_Concepts_of_Travel_Behavior_Research. Accessed 27 Sept 2018

Baslington, H.: Travel socialization: a social theory of travel mode behavior. Int. J. Sustain. Transp. 2(2), 91-114 (2008)

Castro, F.G., Kellison, J.G., Boyd, S.J., Kopak, A.: A methodology for conducting integrative mixed methods research and data analyses. J. Mixed Methods Res. 4, 342-360 (2010)

Chatterjee, K., Goodwin, P., Schwanen, T., Clark, B., Jain, J., Melia, S., Middleton, J., Plyushteva, A., Ricci, M., Santos, G. and Stokes, G.: Young People's travel-what's changed and why? Review and analysis. Report to Department for Transport. UWE Bristol, UK (2018). www.gov.uk/government/publications/ young-peoples-travel-whats-changed-andwhy

Cohen-Blankshtain, G., Rotem-Mindali, O.: Key research themes on ICT and sustainable urban mobility. Int. J. Sustain. Transp. 10(1), 9-17 (2016)

Creswell, J.W., Plano Clark, V.L., Gutmann, M.L., Hanson, W.E.: Advanced mixed methods research designs. In: Tashakkori, A., Teddlie, C. (eds.) Handbook of Mixed Methods in Social and Behavioral Research, pp. 209-240. Sage, Thousand Oaks (2003)

Cresswell, J.W.: Steps in conducting a scholarly mixed methods study, DBER Speaker Series, vol. 48 (2013). http://digitalcommons.unl.edu/dberspeakers/48. Accessed 22 Aug 2018

Delbosc, A., Currie, G.: Causes of youth licensing decline: a synthesis of evidence. Transport Reviews 33(3), 271-290 (2013)

Delbosc, A., Currie, G.: Using discussion forums to explore attitudes toward cars and licensing among young Australians. Transp. Policy 31, 27-34 (2014)

Delbosc, A., Mokhtarian, P.: Face to Facebook: the relationship between social media and social travel. Transp. Policy 68, 20-27 (2018)

Dunedin City Council: Population and demography (2016). http://www.dunedin.govt.nz/your-council/longterm-plan-2015-2016/section-1-major-issues-and-strategies/city-profile/population-and-demography. Accessed 1 Sept 2018

Ewing, R., Carvero, R.: Travel and the built environment: a meta-analysis. J. Am. Plann. Assoc. 76, 265294 (2010)

Falconer, C.L., Leary, S.D., Page, A.S., Cooper, A.R.: The tracking of active travel and its relationship with body composition in UK adolescents. J. Transp. Health 2, 483-489 (2015)

Flamm, M., Kaufmann, V.: Operationalising the concept of motility: a qualitative study. Mobilities 1, 167189 (2006)

Fylan, F., Caveney, L.: Young people's motivations to drive: expectations and realities. Transp. Res. Part F: Traffic Psychol. Behav. 52, 32-39 (2018)

Goodwin, P., Van Dender, K.: 'Peak Car' - themes and issues. Transp. Rev. 33, 243-254 (2013)

Gössling, S.: Interrelationships of internet technologies and transport behaviour. In: Hopkins, D., Higham, J.E.S. (eds.) Low Carbon Mobility Transitions, pp. 219-232. GoodFellow Publishers, Oxford (2016)

Haustein, S., Klöckner, C.A., Blöbaum, A.: Car use of young adults: the role of travel socialization. Transp. Res. Part F: Traffic Psychol. Behav. 12(2), 168-178 (2009)

Huertas Delgado, F.J., Herrador-Colmenero, M., Villa-González, E., Aranda, M.J., Cáceres, M.V., Mandic, S., Chillón, P.: Parental barriers to active commuting to school in Spanish children and adolescents. Eur. J. Public Health 27(3), 416-421 (2017). https://doi.org/10.1093/eurpub/ckw249 
Hopkins, D.: Can environmental awareness explain declining preference for car-based mobility amongst generation Y? An examination of learn to drive behaviours. Transp. Res. Part A: Policy Pract. 94, 149-163 (2016)

Hopkins, D.: Destabilising automobility? The emergent mobilities of generation Y, AMBIO. J. Hum. Environ. 46(3), 371-383 (2017)

Hopkins, D., Higham, J.E.S. (eds.): Low Carbon Mobility Transitions. Goodfellow Publishers, Oxford (2016)

Hopkins, D., Mandic, S.: Perceptions of cycling among high school students and their parents. Int. J. Sustain. Transp. 11(5), 342-356 (2017)

Hopkins, D. \& Stephenson, J.: Generation Y Mobilities: Full Report. Centre for Sustainability. University of Otago, New Zealand (2015). ISBN: 978-0-9941219-3-6; https://hdl.handle.net/10523/5641

Hoffmann, C., Abrahams, C., White, M.P., Ball, S., Skippon, S.M.: What cognitive mechanisms predict travel mode choice? A systematic review with meta-analysis. Transp. Rev. (2017). https://doi. org/10.1080/01441647.2017.1285819

HSCIC: Statistics on obesity, physical activity and diet, England, 2016. Health and Social Care Information Centre (2016). http://content.digital.nhs.uk/catalogue/PUB20562/obes-phys-acti-diet-eng-2016-rep. pdf. Accessed 26 Apr 2016

Imran, M., Pearce, J.: Discursive barriers to sustainable transport in New Zealand cities. Urban Policy Res. 33(4), 392-415 (2015)

International Transport Forum: Reducing transport greenhouse gas emissions, Trends and data 2010, OECD/ITF 2010 (2010)

Jiang, K., Ling, F., Feng, Z., Wang, K., Shao, C.: Why do drivers continue driving while fatigued? An application of the theory of planned behaviour. Transp. Res. Part A 98, 141-149 (2017)

Kerr, J., Rosenberg, D., Sallis, J.F., Saelens, B.E., Frank, L.D., Conway, T.L.: Active commuting to school: associations with environment and parental concerns. Med. Sci. Sports Exerc. 0195-9131, 787-794 (2006)

Kjonniksen, L., Torsheim, T., Wold, B.: Tracking of leisure-time physical activity during adolescence and young adulthood: a 10-year longitudinal study. Int. J. Behav. Nutr. Phys. Act. 5, 69 (2008)

Klöckner, C.A., Matthies, E.: Two Pieces of the Same Puzzle? Script-based car choice habits between the influence of socialization and past behavior. J. Appl. Soc. Psychol. 42(4), 793-821 (2012)

Lorenc, T., Brunton, G., Oliver, S., Oliver, K., Oakley, A.: Attitudes to walking and cycling among children, young people and parents: a systematic review. J. Epidemiol. Community Health 62(10), 852-857 (2008)

Lyons, G.: The reshaping of activities and mobility through new technologies. Editorial for special issue on ICT and the shaping of access, mobility and everyday life. J. Transp. Geogr. 17(2), 81-82 (2009)

Maccoby, E.E.: Historical overview of socialization research and theory. In: Grusec, J.E., Hastings, P.D. (eds.) Handbook of Socialization: Theory and Research. The Guildford Press, New York (2015)

Mandic, S., Williams, J., Moore, A., Hopkins, D., Flaherty, C., Wilson, G., Bengoechea, E.G., Spence, J.C.: Built Environment and Active Transport to School (BEATS) Study: Protocol for a cross-sectional study. BMJ Open 2016(6), e011196 (2016). https://doi.org/10.1136/bmjopen-2016-011196

Mandic, S., Hopkins, D., García Bengoechea, E., Flaherty, C., Williams, J., Sloane, L., Moore, A., Spence, J.C.: Adolescents' perceptions of cycling versus walking to school: understanding the New Zealand context. J. Transp. Health 4, 294-304 (2017)

Matthies, E., Klöckner, C.A.: Car-fixation, socialization, and opportunities for change. In: Hickman, R., Givoni, M., Bonilla, D., Banister, D. (eds.) Handbook on Transport and Development. Edward Elgar Publishing Limited, Cheltenham (2015)

Meaton, J., Kingham, S.: Children's perceptions of transport modes: car culture in the classroom? World Transp. Policy Pract. 4(2), 12-16 (1998)

Ministry of Transport: Comparing travel modes: New Zealand household travel survey 2011-2014 (2015). http://www.transport.govt.nz/assets/Uploads/Research/Documents/Comparing-travel-modes-2015.pdf. Accessed 1 Sept 2018

Ministry of Education: School deciles (2016). http://www.education.govt.nz/school/running-a-school/resou rcing/operational-funding/school-decile-ratings/. Accessed 1 Sept 2018

Muromachi, Y.: Experiences of past school travel modes by university students and their intention of future car purchases. Transp. Res. Part A: Policy Pract. 104, 209-220 (2017)

NZTA: New tools to help parents battle the biggest killer of NZ teens (2011). https:/www.nzta.govt.nz/ media-releases/new-tools-to-help-parents-battle-the-biggest-killer-of-nz-teens/. Accessed 11 June 2011

OECD: OECD economic surveys New Zealand June 2013 overview (2013)

OECD: OECD economic surveys New Zealand, June 2015 overview (2015) 
Ottelin, J., Heinonen, J., Junnila, S.: Greenhouse gas emissions from flying can offset the gain from reduced driving in dense urban areas. J. Transp. Geogr. 41, 1-9 (2014)

Pluye, P., Bengoechea, E.G., Granikov, V., Kaur, N., Li Tang, D.: A world of possibilities in mixed methods: Review of the combinations of strategies used to integrate the phases, results, and qualitative and quantitative data. Int. J. Multiple Res. Approaches 10(1), 41-56 (2018). https://doi.org/10.29034/ijmra .$v 10 n 1 \mathrm{a} 3$

Preval, N., Chapman, R., Howden-Chapman, P.: For Whom the City? Housing and Locational Preferences in New Zealand. Sizing Up the City. Steele Roberts Publishers, Wellington (2010)

Rosqvist, L.S., Hiselius, L.W.: Online shopping habits and the potential for reductions in carbon dioxide emissions from passenger transport. J. Clean. Prod. 131, 163-169 (2016)

Schönhammer, R.: Auto, geschlecht und sex [car, gender and sex]. In: Tully, C.J. (ed.) Erziehung zur mobilität. Jugendliche in der automobilen gesellschaft, pp. 141-156. Campus, Frankfurt am Main (1999)

Schwartz, S.H.: Normative influence on altruism. In: Berkowitz, L. (ed.) Advances in Experimental Social Psychology, vol. 10, pp. 221-279. Academic Press, New York (1977)

Schwanen, T.: Rethinking resilience as capacity to endure. City 20(1), 152-160 (2016)

Schwanen, T., Lucas, K.: Understanding auto motives. In: Lucas, K., Blumenberg, E., Wein Berger, R. (eds.) Auto Motives: Understanding Car Use Behaviours. Emerald, London (2011)

Sigurdardottir, S.B., Kaplan, S., Møller, M.: The motivation underlying adolescents' intended time-frame for driving licensure and car ownership: a socio-ecological approach. Transp. Policy 36, 19-25 (2014)

Statistics New Zealand: 2013 census Quickstats about a place: Dunedin City (2013). http://archive.stats .govt.nz/Census/2013-census/profile-and-summary-reports/quickstats-about-a-place.aspx?request_ value $=15022 \&$ tabname $=$ Transport. Accessed 1 Sept 2018

Stead, D., Pojani, D.: The urban transport crisis in emerging economies: a comparative overview. In: Pojani, D., Stead, D. (eds.) The Urban Book Series, pp 283-295 (2016)

Thigpen, C., Handy, S.: Driver's licensing delay: a retrospective case study of the impact of attitudes, parental and social influences, and intergenerational differences. Transp. Res. Part A: Policy Pract. 111, 24-40 (2018)

Triandis, H.C.: Subjective culture and interpersonal relations across cultures. Ann. N. Y. Acad. Sci. 2385(1), 418-434 (1977)

Trost, S., Owen, N., Bauman, A., Sallis, J., Brown, W.: Correlates of adults' participation in physical activity: review and update. Med. Sci. Sports Exerc. 34(12), 1996-2001 (2002)

Van Acker, V., Van Wee, B., Witlox, F.: When transport geography meets social psychology: toward a conceptual model of travel behaviour. Transp. Rev. 30(2), 219-240 (2010)

Veal, A.J.: Research Methods for Leisure and Tourism: A Practical Guide. Pearson Education, New York (2006)

Le Vine, S., Polak, J.: Factors associated with young adults delaying and forgoing driving licenses: results from Britain. Traffic Injury Prev. 15(8), 794-800 (2014). https://doi.org/10.1080/15389 588.2014.880838

Yang, Z., Jia, P., Liu, W., Yin, H.: Car ownership and urban development in Chinese cities: a panel data analysis. J. Transp. Geogr. 58, 127-134 (2017)

Publisher's Note Springer Nature remains neutral with regard to jurisdictional claims in published maps and institutional affiliations.

Debbie Hopkins is an Associate Professor in Human Geography at the University of Oxford, appointed between the Sustainable Urban Development programme, the School of Geography and the Environment and the Transport Studies Unit. Her research is broadly concerned with decarbonising transport systems. More specifically, Debbie researches young adults travel practices, sociotechnical innovations, low-carbon transitions, and mobile labour.

Enrique García Bengoechea is currently the Dean's Fellow in Physical Activity and Health in the Faculty of Education and Health Sciences at the University of Limerick, Ireland. Previously he has held academic and research appointments at the Alberta Centre for Active Living, McGill University, University of Western Sydney and Victoria University in Melbourne. His main research interests are physical activity and health promotion and implementation science.

Sandra Mandic is an Associate Professor at the University of Otago, New Zealand, where she leads the Active Living Laboratory and Built Environment and Active Transport to School Research Programme. 
Interdisciplinary and multi-sector approach to physical activity and health with the links to transportation, built environment and sustainability inspire Sandy's academic activities. Sandy's academic training and professional experiences span Europe, Canada, United States and New Zealand. 